\section{Antidepressants and public health in Iceland}

\author{
Time series analysis of national data \\ TÓMAS HELGASON, HELGI TÓMASSON and TÓMAS ZOËGA
}

\begin{abstract}
Background Major depressive disorder is the second leading cause of disability-adjusted life-years in developed regions of the world and antidepressants are the third-ranking therapy class worldwide.
\end{abstract}

Aims To test the public health impact of the escalating sales of antidepressants.

Method Nationwide data from Iceland are used as an example to study the effect of sales of antidepressants on suicide, disability, hospital admissions and outpatient visits.

\section{Results Sales of antidepressants} increased from 8.4 daily defined doses per 1000 inhabitants per day in 1975 to 72.7 in 2000 , which is a user prevalence of $8.7 \%$ for the adult population. Suicide rates fluctuated during 1950-2000 but did not show any def inite trend. Rates for outpatient visits increased slightly over the period 1989-2000 and admission rates increased even more. The prevalence of disability due to depressive and anxiety disorders has not decreased over the past 25 years.

\section{Conclusions The dramatic increase in} the sales of antidepressants has not had any marked impact on the selected public health measures. Obviously, better treatment for depressive disorders is still needed in order to reduce the burden caused by them.

\section{Declaration of interest None.}

Antidepressants were introduced in the late 1950s and their use was relatively limited until the introduction of the selective serotonin reuptake inhibitors (SSRIs) in the late 1980s. Since then

'widely publicized emphasis on recognition and treating depression and... development of many new pharmacotherapies have contributed to explosive growth in antidepressant prescribing and increasing pharmacy costs for health plans' (Williams et al, 2000).

Major depressive disorder is the second leading cause of disability-adjusted lifeyears in developed regions of the world (Murray \& Lopez, 1996) and antidepressants, the third-ranking therapy class worldwide, experienced an $18 \%$ sales growth in 2000, with North America being the dominant market (IMS Health, 2002). However, the question remains: has this had any impact on public health and the burden of depression? Analysis of official data from Iceland, with its extensive use of antidepressants, can contribute to answering this question. We have examined the data in order to address the following questions: how much has the sale of antidepressants increased since SSRIs were introduced in Iceland by the end of 1988, and what is the proportional increase in the sale of these and other more recent antidepressants; has the increased use of antidepressants affected the number of psychiatric out-patient visits and the extent of hospital treatment; and has the increased use of antidepressants affected suicide rates or the prevalence of disability?

\section{METHOD}

\section{Setting}

Iceland has a population of 286000 (in 2001) with one active physician per 290 inhabitants, including 195 physicians in primary care and 55 psychiatrists. The State Social Security Institute covers the majority of health care costs and the patients pay a part of the cost for medication and outpatient visits.

\section{Data}

The following nationwide data were collected from a range of official sources.

(a) The Ministry of Health provided data on the amount of medication sold nationwide annually in standard units, daily defined doses per 1000 inhabitants per day (DDD/1000/day), from 1975 to 2000 as well as on the retail price of each type of medication. Antidepressants include tricyclic and tetracyclic antidepressants, monoamine oxidase inhibitors, SSRIs and other antidepressants such as venlafaxine, but exclude stimulants.

(b) The number of out-patient visits was collected from psychiatric department reports and State Social Security Institute reports for the period 1989-2000.

(c) The number of admissions to psychiatric departments, the number of in-patient days and the number of in-patients annually for the period 1989-2000 were obtained from hospitals.

(d) The State Social Security Institute supplied information on the prevalence of the disability pension in 1976 and 2001.

(e) Official statistics on suicides (Skýrsla, 1996) and information from the Department of Forensic Medicine were obtained for the period 1950-2000.

(f) Increasing consumption of alcoholic beverages might influence the number of suicides, so data on the annual sales of alcohol per capita for the period 1950-2000 were obtained (Statistics Iceland, 2002).

Until 1993, very few children and adolescents under the age of 15 years were prescribed antidepressants, and in that same year only $0.8 \%$ of prescriptions were issued to children under this age. According to a recent limited prescription survey, $6.7 \%$ of the antidepressants were filled for this age group (Skýrsla, 1999). Therefore a $1 \%$ annual increase was assumed and deducted from the total quantities sold when estimating the number of daily defined doses per 1000 inhabitants aged 15 years or more during 1994-2000.

\section{Statistical analysis}

For analyses of time series count data, a quasi-Poisson model was used. The 
logarithm of expected counts is expressed by Equation (1):

$$
\begin{aligned}
& \log \left[E\left(N_{t} \mid N_{t-1}, N_{t-2}\right)\right] \\
& =\beta_{0}+\beta_{1} \log \left(\operatorname{pop}_{t}\right)+\phi_{1} \log \left(N_{t-1}\right) \\
& \quad+\phi_{2} \log \left(N_{t-2}\right)
\end{aligned}
$$

where $N_{t}$ denotes the count in year $t ; \operatorname{pop}_{t}$ is the population size in year $t$; and $E\left(N_{t} \mid N_{t-1}\right.$, $N_{t-2}$ ) denotes the conditional expected number of counts in year $t$ given the counts in years $t-1$ and $t-2$. The purpose of the logarithmic terms $\log \left(N_{t-1}\right)$ and $\log \left(N_{\mathrm{r}-2}\right)$ is to allow for possible cyclical behaviour, which could be due to several reasons (e.g. systematic effects in the registration of suicides or latent socio-economic variables). The autoregressive parameters $\phi_{1}$ and $\phi_{2}$ characterise possible cycles in the number of suicides. Spectral time-series analysis (Harvey, 1993) was used to estimate the length of such cycles. The model in Equation (1) assumes that the expected count is proportional to a power of the population size. Thus, the parameter $\beta_{1}$ describes the trend structure of the series and $\beta_{0}$ is an intercept. The diagnostics of the model were performed by analysing the scaled residuals, $\nu$, defined by Equation (2):

$$
\nu_{t}=\left[N_{t}-E\left(N_{t}\right)\right] / E\left(N_{t}\right)^{1 / 2}
$$

The statistical inference was corrected for eventual overdispersion, i.e. the variance being greater than the mean, by estimating a quasi-Poisson model of type (1). Eventual misspecification of the model shows up in the scaled residuals. An important omitted variable should show association to them. The Ramsey-RESET test (Gujarati, 1995) was used to test the model specification, such as functional form and eventual missing variables.

The possibility of autocorrelation was addressed by inclusion of autoregressive terms (Cameron \& Trivedi, 1998). The statistical program $\mathrm{R}$ was used for numerical calculations (Ihaka \& Gentleman, 1996).

\section{RESULTS}

\section{Sales of antidepressants and suicides}

From 1989 the increase in sales of psychopharmacological medication was exponential by about $16.4 \%$ per year, with a close to perfect fit for the period 1995-2000.
Table I Medication sold in 1989 and 2000

\begin{tabular}{lrrrrr}
\hline Medication & \multicolumn{2}{c}{$\begin{array}{c}\text { Quantity } \\
\text { (DDD/1000/day) }\end{array}$} & & \multicolumn{2}{c}{$\begin{array}{c}\text { Cost } \\
\text { (Million Ikr, 2000 price) }\end{array}$} \\
\cline { 2 - 3 } \cline { 5 - 6 } & 1989 & 2000 & & 1989 & 2000 \\
\hline All & 664.5 & 983.8 & & 6293 & 10465 \\
Psychopharmacological & 84.5 & 162.2 & & 503 & 1509 \\
Antidepressants & 14.9 & 72.7 & & 184 & 1033 \\
\hline
\end{tabular}

DDD, daily defined doses.
The increase can be ascribed to new antidepressants, mainly SSRIs, that were introduced to the market in Iceland by the end of 1988. During the period 1989-2000 the total quantity of medication sold increased by $48 \%$, the quantity of antidepressants increased by $388 \%$ and the quantity of other psychopharmacological medication, mainly hypnotics, increased by $92 \%$. The cost of all medication calculated according to the consumer price index in the year 2000 increased by $66 \%$, whereas in the same year the use of antidepressants reached $72.7 \mathrm{DDD} / 1000 /$ day and the cost had escalated by $461 \%$ since 1989 (Table 1). This is equivalent to an estimated user point prevalence of $8.7 \%$ for the adult population (aged 15 years or more) provided that all the patients are compliant in taking one defined dose per day. The sales of antidepressants in Iceland increased gradually from 1981, when tetracyclic antidepressants were introduced, up until 1985. Thereafter it remained relatively stable, at around $15 \mathrm{DDD} / 1000 /$ day, up until 1990; since then it has increased very markedly, mainly due to the addition of SSRIs to older antidepressants. The sales of tricyclic antidepressants have been reduced gradually by $21 \%$ to $8.6 \mathrm{DDD} / 1000 /$ day in the year
2000, whereas the sales of SSRIs have continued to escalate to $49.2 \mathrm{DDD} / 1000 /$ day, as can be seen from Fig. 1. From mid1996 venlafaxine and other new antidepressants have added to the constant increase in antidepressant sales (venlafaxine sales were $15 \mathrm{DDD} / 1000 /$ day in the year 2000).

Official figures on the sales of antidepressants have been available only since 1975 and are shown in Fig. 1, along with annual suicide rates and per capita sales of alcohol for the period 1950-2000. An example of model output according to Equation (1) is given in Table 2, which suggests that the number of suicides has increased slightly more than the corresponding increase in population and, by spectral analysis, estimates of the autoregressive parameters $(0.45$ and -0.33$)$ suggest a cycle of about 5-6 years. The data do not allow us to determine whether this is due to some events within a year or whether there are genuine cycles in the process. The standard errors in Table 2 are corrected for overdispersion. Residual analysis showed that the process is remarkably constant over a 50 -year period. The scaled residuals showed no autocorrelation after including the two autoregressive terms

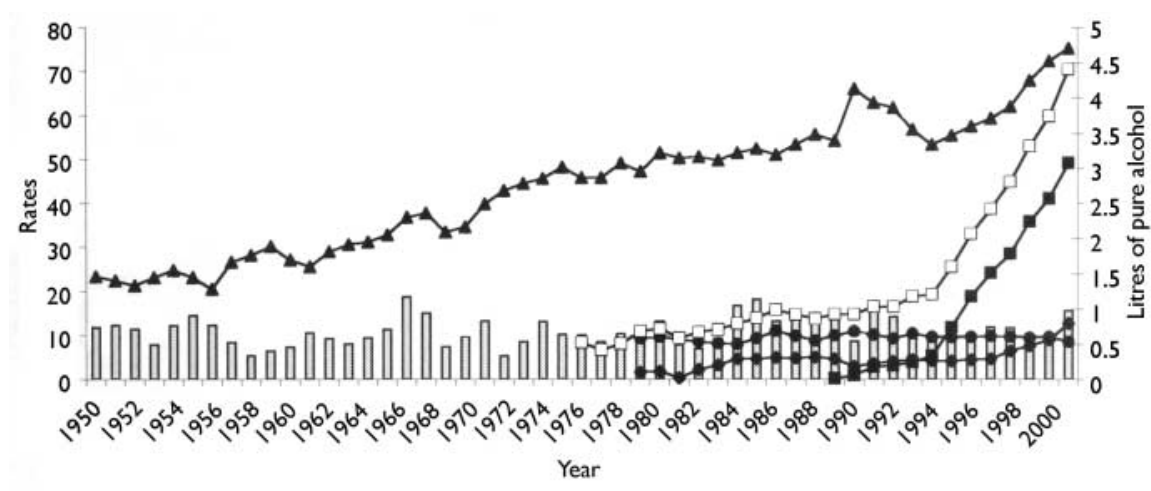

Fig. I Suicide rates per 100000 inhabitants (bars), sales of pure alcohol per capita in 1950-2000 (- - ) and sales of antidepressants in daily defined doses/1000/day during 1975-2000: - - tricyclic antidepressants;

- selective serotonin reuptake inhibitors; $\neg$ other antidepressants; $-\square-$ total antidepressants. 
Table 2 Estimates of a quasi-Poisson model (Equation (I)) for the number of suicides

\begin{tabular}{lccrr}
\hline Variable & Estimate & $\begin{array}{c}\text { Corrected standard } \\
\text { error }\end{array}$ & $t$ & $P$ \\
& & 3.38 & -3.68 & 0.001 \\
Constant & -12.44 & 0.30 & 4.10 & $<0.001$ \\
Log (Population at time $t$ ) & 1.24 & 0.14 & 3.20 & 0.003 \\
Log (Number of suicides at time $t-1)$ & 0.45 & 0.14 & -2.36 & 0.023 \\
Log (Number of suicides at time $t-2)$ & -0.33 & & & \\
\hline
\end{tabular}

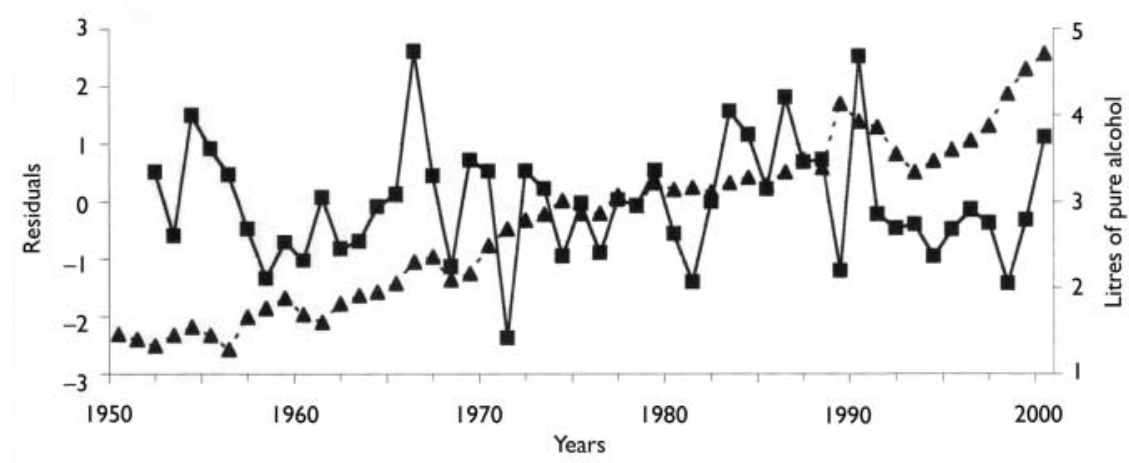

Fig. 2 Standardised residuals from the model used to explain the number of suicides $(--)$ and annual per capita alcohol sales (-- A--) during 1950-2000.

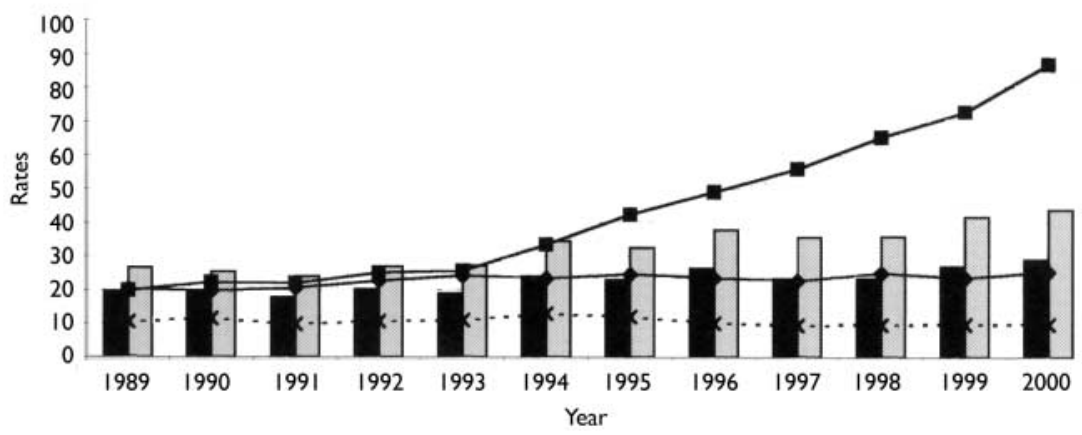

Fig. 3 Sales of antidepressants in daily defined doses per 1000 inhabitants aged I5+per day $(--)$ and use of psychiatric services by adults during 1989-2000: patients admitted per 10000 inhabitants aged 15 years or more; total number of admissions per 10000 inhabitants aged 15 years or more; -- $\not$ - - in-patient days per 100 inhabitants aged 15 years or more; $\_$out-patient consultations per 100 inhabitants aged 15 years or more.

in the model. A Ramsey-RESET test did not indicate that the model was wrongly specified $(P=0.98)$. Consequently, there is no indication that a trend or some simple function of time is missing from the model as an explanatory variable, particularly not the increased sales of antidepressants.

Figure 2 shows a graph of standardised residuals of the model. A possible explanatory variable that might add information on the frequency of suicides should have something in common with what is not explained by the model, i.e. the residuals. To illustrate this point, a graph of the annual average sales of pure alcohol per inhabitant is also shown in Fig. 2. The Ramsey-RESET test did not suggest that the model was wrongly specified. To illustrate this further the model was reestimated with alcohol consumption per capita and its lagged value added to the model. The impact was only marginal (a likelihood ratio test statistic of 0.42 ; $\chi^{2}=0.66$; d.f. $=2$ ), which is not surprising considering the result of the RamseyRESET test.

The population in the year 2000 was about 283000 and the average suicide rate was $11 / 100000$, so the expected annual number of suicides is around 30 . The overdispersion coefficient in the model containing autoregressive terms is approximately 1.5, therefore the standard deviation of the yearly number of suicides is the square root of $1.5 \times 30$, which is about 7 . In a model without autoregressive terms the overdispersion is about 1.9 , which gives a standard deviation in the region of 8 . Thus, the autoregressive parameters have limited impact on predicting the number of suicides.

\section{Sales of antidepressants and psychiatric out-patient visits and hospital admissions}

In spite of the dramatic increase in the sales of antidepressants, the rates of psychiatric out-patient consultations and in-patient treatment for depressive disorders increased (Fig. 3). After correcting for the increase in the population aged 15 years or more, the number of patients admitted increased by about $3.9 \%$ annually. Similarly, after correcting for the increase in population the admission rates increased by $5.4 \%$ per year (i.e. each patient was admitted more often). Furthermore, the number of outpatient consultations increased by $2 \%$ per year during the period 1989-2000. The total duration of in-patient treatment for depressive disorders per 100 inhabitants decreased by $1.1 \%$ per year whereas that for psychiatric disorders in general decreased by $3.6 \%$ annually as the number of available beds decreased.

\section{Disability}

The proportion of the general population claiming disability pension because of depressive and anxiety disorders increased from $0.4 \%$ to $0.7 \%$, as it did for other disorders over the 25-year period of 1976-2001; however, it remained similar as a proportion of all disability (i.e. about $13 \%)$.

\section{DISCUSSION}

The sales of antidepressants per capita in Iceland in 2000 were probably comparable to those in the USA (IMS Health, 2002). The retail cost of antidepressants increased in Iceland by $460 \%$ during the past 12 
years but there are no data available to show that this has offset other costs. The increased cost can be ascribed to the SSRIs and other newer antidepressants because the cost of the older drugs has decreased. The marked worldwide increase in the use of antidepressants and their cost has been the source of much discussion in relation to the cost-effectiveness and possible advantages of the new medications versus the more traditional or other forms of treatment (Agency for Health Care Policy and Research, 1999; Williams et al, 2000).

\section{Sales of antidepressants and the prevalence of depressive disorders}

Recently, the International Consensus Group on Depression and Anxiety stated that depression was currently underrecognised and undertreated, particularly in young adults (Ballenger et al, 1999). The results of the present study hardly support this as regards treatment with antidepressants. The sales of antidepressants in Iceland in the year 2000 corresponded to a user prevalence of $8.7 \%$ among those aged 15 years or more, which is within the range of estimates for the community prevalence of depressive disorders: $4-10 \%$ among adults (Bebbington et al, 1998; Helgason, 1990). Depressive disorders cause considerable impairment, result in increased mortality, reduce the healthrelated quality of life (Simon et al, 1998) and are costly for the patients, their families and society. The direct cost of treating depressive disorders in Iceland, the population of which is approximately onethousandth of that in the USA, was estimated to be equivalent to $£ 18.6$ million in 1998 (Skýrsla, 1999) and about 27\% of this amount was ascribed to antidepressants, mainly SSRIs.

The prevalence of subsyndromal depression or of depressive symptoms is considerably higher than that of depressive disorders, being 16-25\% (Helgason, 1990). Depressive disorders and symptoms are very common in primary care and are often comorbid with physical disorders (Kisely \& Goldberg, 1996); they are also mixed with anxiety disorders, for which antidepressants have been used increasingly in recent years.

During the past $10-15$ years new generations of antidepressants have been developed and marketed energetically. At the same time, awareness campaigns have been launched to combat depression
(Paykel et al, 1998) and to prevent suicide in a number of countries (Taylor et al, 1997). In addition, guidelines for treating depressive disorders have been issued (American Psychiatric Association, 2000). These developments might have been expected to have a public health impact by reducing disability, morbidity and mortality due to depressive disorders, even more so as the new medications are simpler to administer and more likely to be given in adequate dosages than tricyclic antidepressants. However, the cost for society has not been reduced and the impact on public health is limited.

Far fewer antidepressants are taken than are sold (prescribed), therefore prevalence estimates based on sales data are too high due to limited compliance. In a recent community survey the self-reported use of antidepressants (in DDD/1000/day) was estimated to correspond to about $54 \%$ of the official sales figures (Helgason et al, 2003). The reasons for many of the prescriptions are not clear, as primary care physicians have probably not diagnosed depressive disorder in more than $40-50 \%$ of patients prescribed antidepressants (Skýrsla, 1999; Ornstein et al, 2000). It should be noted, however, that antidepressants are being used increasingly for other disorders, such as some anxiety disorders and chronic pain.

\section{Admissions, out-patient visits and disability}

Admission rates for in-patient treatment of depressive disorders have increased, partly because of more readmissions and partly because more patients are admitted. The number of in-patient days used for depressive disorders has decreased insignificantly but in contrast, the decrease in in-patient days for psychiatric disorders in general has been quite marked. At the same time as these trends were occurring, the availability of psychiatric hospital beds was also decreasing. The increased annual admission rate may indicate increasing acceptance of treatment and decreasing stigmatisation, as well as a possible lower admission threshold for depressive disorders because beds for other disorders might have been freed up owing to the tendency to treat people with psychosis in the community. The rates for psychiatric out-patient visits increased, thus it is conceivable that the new antidepressants have not stopped the need to refer intractable cases of depression for speciality treatment. It has been found in clinical studies that adequate treatment can be expected to alleviate physical and psychosocial impairment in patients with depression and to improve their quality of life (Simon et al, 1998). Despite extensive pharmacological treatment, the prevalence rates for disability due to depressive and anxiety disorders increased, although not as a proportion of total disability. It should be noted that the increased prevalence of disability pension between 1996 and 2001 is related to changes in disability assessment.

\section{Suicide rates}

Suicide rates in Iceland have fluctuated roughly as an autoregressive Poisson process with a dispersion coefficient of 1.5 during the latter half of the 20th century, remaining on average about 11/100000. The age and gender distribution of those who died by suicide may have changed during this period, but the overall rates have not been affected by the sales of antidepressants, which have increased ninefold since 1975 . It is unlikely, according to our findings, that a reduction in the sales of antidepressants would affect the rates of psychiatric service use and suicide.

Unemployment has not been a problem in Iceland during the study period, with less than $1 \%$ of the labour force being out of work most of the time. However, in 1969 unemployment rose to $2.5 \%$, only to decrease again and then rise to $5 \%$ in 1995. In 1999 it had fallen once more to less than $2 \%$. One-third or less of those unemployed were out of work for more than 6 months (Statistics Iceland, 2002). The Ramsey-RESET test (Gujarati, 1995) does not indicate that unemployment and other unknown variables have had an effect on the number of deaths by suicide.

One of the main features of time series models is to filter out trends and cycles. It is conceivable that alcohol consumption, unemployment and other variables affect suicide rates. If that is the case, the residual diagnostics indicate that they are already sufficiently included in the trend-and-cycle component of the model. Thus, it is not likely that a counteracting effect of alcohol and antidepressants can be invoked as an explanation for not finding any effect of the huge increase in antidepressant use on suicide rates in Iceland.

Suicide rates in the population are a very crude measure of the public health 
impact of antidepressant medication. Suicide rates have decreased during the 1990 s in some countries, especially in those with national strategies (Taylor et al, 1997) aimed at preventing suicide, such as the UK (McClure, 2000), Finland, Norway and Sweden (Isacsson, 2000), in Denmark (Isacsson, 2000), which did not have such a strategy (Taylor et al, 1997), and in the USA (Maris, 2002). However, it may be noted that the suicide rate in Norway has remained unchanged at the 1980 level since 1995 (Retterstöl et al, 2002), in spite of increasing sales of antidepressants. The results of a Swedish study suggested that the increasing use of antidepressants was a contributing factor to the decreasing suicide rates (Isacsson, 2000). The results of the present study do not support this suggestion because a hypothetical missing explanatory variable (i.e. increased sales of antidepressants) did not correlate with the residuals of the statistical model used. Although clinical psychiatrists are convinced that suicides can be prevented in individual patients by adequate treatment, it has been difficult to prove in large studies (Khan et al, 2000).

It is of major importance to study the effects of the extensive prescribing of antidepressants to the large number of people obtaining them who do not have a diagnosed depressive disorder. Data on newer pharmacotherapies for patients with subsyndromal or mixed anxiety-depression and for special populations such as children and adolescents are insufficient to guide treatment decisions (Agency for Health Care Policy and Research, 1999). The results of such studies could help to elucidate whether antidepressants improve the recipients' quality of life and/or prevent later development of major depression or other impairment.

There are no signs that the rapidly escalating use of antidepressants is reducing the burden of depressive disorders (Moncrieff, 2002). The present study has not revealed any marked impact of the dramatic increase in sales of antidepressants on psychiatric aspects of public health at the macro-level, except bringing the most common mental disorders into the mainstream of medical treatment for the benefit of patients, but at a substantial increase in medication cost. This has possibly reduced stigmatisation and brought about an increased acceptance of the need for treatment, as is reflected in the growing number of patients admitted to hospital psychiatric

\section{CLINICAL IMPLICATIONS}

- The new antidepressants have brought patients with depression into the mainstream of medical treatment.

- Recognition of patients who will benefit from treatment with antidepressant medication has to be improved.

- Patients being treated with antidepressants need a close follow-up by their general practitioners or psychiatrists to ensure that they use the medication effectively.

\section{LIMITATIONS}

Data on the distribution of national sales of medication by demographic and clinical factors was not available.

A diagnostic breakdown of out-patient consultations was not available, although it can be assumed that the majority were probably for depressive and anxiety disorders.

- Despite their importance, public health indicators are a crude measure for the outcome of antidepressant treatment.

TÓMAS HELGASON, MD, Faculty of Medicine, University of Iceland; HELGI TÓMASSON, PhD, Faculty of Economics and Business Administration, University of Iceland; TÓMAS ZOËGA, MD, Faculty of Medicine, University of Iceland, Reykjavik, Iceland

Correspondence: Tómas Helgason, 4 Midleiti, IS- 103 Reykjavik, Iceland. Tel: +354 5532287; e-mail: tomashe@isholf. is

(First received 14 March 2003, final revision 13 August 2003, accepted 3 September 2003)

departments. But because the public health indicators studied are based on administrative data, more detailed studies on distress, quality of life, work performance and short-term absenteeism might reveal a greater impact (Simon et al, 1998).

\section{ACKNOWLEDGEMENTS}

Eggert Sigfússon at the Ministry of Health and Social Security supplied data on the sales of medication, Gunnlaugur Geirsson at the University of Iceland supplied information on the number of suicides for 1995-2000 and Sigurður Thorlacius at the State Social Security Institute supplied data on the prevalence of disability. This paper was prepared while T.H. was a visiting scholar at the Department of Mental Hygiene, Johns Hopkins School of Public Health, Baltimore, USA

\section{REFERENCES}

Agency for Health Care Policy and Research (1999) Treatment of depression - newer pharmacotherapies. Summary. In Evidence Report/Technology Assessment. Number 7, March 1999. Rockville, MD: AHCPR. http: // www.ahcpr.gov/clinic/deprsumm. htm
American Psychiatric Association (2000) Practice guidelines for the treatment of patients with major depressive disorder (revision). American Journal of Psychiatry, 157 (suppl. 4), I-45.

Ballenger, J., Davidson, R., Lecrubier, Y., et al (1999) Consensus statement on the primary care management of depression from the International Consensus Group on Depression and Anxiety. Journal of Clinical Psychiatry, 60 (suppl. 7), 54-61.

Bebbington, P., Dunn, G., Jenkins, R., et al (1998) The influence of age and sex on the prevalence of depressive conditions: report from the National Survey of Psychiatric Morbidity. Psychological Medicine, 28, 9-19.

Cameron, A. \& Trivedi, P. (1998) Regression Analysis of Count Data. Cambridge: Cambridge University Press.

Gujarati, D. (1995) Basic Econometrics. New York: McGraw Hill.

Harvey, A. (1993) Time Series Models (2nd edn). New York: Harvester Wheatsheaf.

Helgason, T. (1990) Depressionernes epidemiologi [The epidemiology of depressions]. Nordisk Psykiatrisk Tidsskrift, 44, 3-12.

Helgason, T., Tómasson, K. \& Zoëga,T. (2003) Algengi og dreifing notkunar geðdeyfðar-kvída-og svefnlyfja [Prevalence and distribution of antidepressant, anxiolytic and hypnotic use in 200I] Laknablaðið, 89, 15-22. 
Ihaka, R. \& Gentleman, R. (1996) R: a language for data analysis and graphics. Journal of Computational and Graphical Statistics, 5, 299-314.

IMS Health (2002) IMS Drug Monitor. Antidepressants Vol. 2002. The Global Health Care Information Company. http://www.imshealth.com/ims/portal/ front/articleC/0,2777,6025_3665_1003594,00.html

Isacsson, G. (2000) Suicide prevention - a medical breakthrough? Acta Psychiatrica Scandinavica, 102, 113-117.

Khan, A., Warner, H. \& Brown, W. (2000) Symptom reduction and suicide risk in patients treated with placebo in antidepressant clinical trials: an analysis of the Food and Drug Administration database. Archives of General Psychiatry, 57, 31I-3I7.

Kisely, S. R. \& Goldberg, D. P. (1996) Physical and psychiatric comorbidity in general practice. British Journal of Psychiatry, 169, 236-242.

Maris, R. (2002) Suicide. Lancet, 360, 319-326.

McClure, G. M. G. (2000) Changes in suicide in England and Wales, 1960-1997. British Journal of Psychiatry, 176, $64-67$
Moncrieff, J. (2002) The antidepressant debate. British Journal of Psychiatry, 180, 193-194.

Murray, C. \& Lopez, A. (1996) The Global Burden of Disease. A Comprehensive Assessment of Mortality and Disability from Diseases, Injuries, and Risk Factors in 1990 and Projected to 2020. Boston, MA: The Harvard School of Public Health on behalf of the World Health Organization and the World Bank.

\section{Ornstein, S., Stuart, G. \& Jenkins, R. (2000)}

Depression diagnoses and antidepressant use in primary care practices: a study from the Practice Partner Research Network (PPRNet). Journal of Family Practice, 49, 68-72.

Paykel, E. S., Hart, D. \& Priest, R. G. (1998) Change in public attitudes to depression during the Defeat Depression Campaign. British Journal of Psychiatry, 173 519-522.

Retterstöl, N., Ekeberg, Ö. \& Mehlum, L. (2002) Selvmord - et personlig og samfunnsmessig problem [Suicide - A Personal and Social Problem]. Oslo: Gyldendal.
Simon, G., Katon, W., Von Korff, M., et al (1998) Impact of improved depression treatment in primary care on daily functioning and disability. Psychological Medicine, 28, 693-70I.

Skýrsla (1996) Könnun á tið̀ni og orsökum sjálfsvíga á Íslandi og tillögur til úrbóta [Survey of Frequency and Causes of Suicide in Iceland]. Reykjavik: Menntamálaráduneytið (Department of Education).

Skýrsla (1999) Notkun geðdeyfoarlyfja og punglyndisraskanir [Use of antidepressants and depressive disorders]. Laknablaðid, 85 (suppl. 38), 3-26.

Statistics Iceland (2002) Statistics Iceland. http: // www. hagstofa. is/template44.asp and http:// www. hagstofa. is/template4l.asp/

Taylor, S., Kingdom, D. \& Jenkins, R. (1997) How are nations trying to prevent suicide? An analysis of national suicide prevention strategies. Acta Psychiatrica Scandinavica, 95, 457-463.

Williams, J. J., Mulrow, C., Chiquette, E., et al (2000) A systematic review of newer pharmacotherapies for depression in adults: evidence report summary. Annals of Internal Medicine, I32, 743-756. 